\title{
Ficção seriada televisiva, jornalismo político e construção do real: hipóteses a partir de Greimas
} TV serial fiction, political journalism and construction of reality: some hypotheses from Greimas' perspective

\author{
Paolo Demuru ${ }^{1}$
}

\footnotetext{
${ }^{\mathrm{T}}$ Professor Titular do Programa de Pós-Graduação em Comunicação da Universidade Paulista. Pós-doutor em Comunicação e Semiótica pela Pontifícia Universidade Católica de São Paulo (PUC-SP) e em Comunicação pela Universidade Federal de Pernambuco. Doutor em Semiótica pela Universidade de Bologna e doutor em Semiótica e Linguística Geral pela Universidade de São Paulo. Autor do livro Essere in gioco. Calcio e cultura tra Brasile e Itália (Bononia University Press, 2014) e de diversas publicações científicas internacionais. Membro da Associazione Italiana di Studi Semiotici e do Laboratorio Romano di Semiotica, graduou-se em Scienze della Comunicazione pela Universidade de Roma La Sapienza, com estágio de pesquisa realizado no Centro de Pesquisas Sociossemióticas da PUC-SP, do qual é ainda pesquisador ativo. E-mail: paolodemuru@gmail.com
} 
Resumo: o objetivo deste artigo é refletir, com base nos pilares epistemológicos da semiótica de Greimas, sobre o papel das relações entre seriados televisivos e jornalismo político no processo de formação daquilo que, em uma dada esfera sociocultural, é percebido como "mundo real". Em particular, foca-se nos elos entre o drama House of Cards e a cobertura dos eventos que antecederam e seguiram o impeachment da ex-presidente do Brasil, Dilma Rousseff, a fim de mostrar como a interseção entre os dois universos discursivos contribui, hoje, para forjar a percepção de uma realidade política e cotidiana cada vez mais serializada e dramatizada, construída e fruída nos moldes da ficção seriada televisiva.

Palavras-chave: Greimas; ficção seriada televisiva; jornalismo político; construção do real; epistemologia da comunicação.

Abstract: based on the epistemological pillars of Greimas' semiotics, this paper aims to reflect on the role of relations between TV series and political journalism in the process of construction of what, in a given sociocultural sphere, is perceived as "real world". In particular, it focuses on the links between the political drama House of Cards and the coverage of events that preceded and followed the impeachment of Brazil's former president, Dilma Rousseff, in order to show how the intersection between those two discursive universes contributes, nowadays, to forge the perception of an increasingly serialized and dramatized political and daily reality, constructed and consumed along the lines of the TV serial fiction.

Keywords: Greimas; TV serial fiction; political journalism; construction of reality; epistemology of communication. 


\section{Introdução}

A partir das considerações desenvolvidas por Algirdas Julien Greimas em seu ensaio Condições para uma semiótica do mundo natural (GREIMAS, 1975a) e no diálogo com Paul Ricoeur (GREIMAS; RICOEUR, 2000), proponho explorar, neste artigo, o papel das relações interdiscursivas entre os seriados televisivos e o jornalismo político contemporâneos no processo de formação daquilo que, em uma dada esfera sociocultural, é tido e entendido como "mundo real" ou "verdadeiro".

Em particular, deter-me-ei nos elos entre o political drama (drama político) House of Cards, produzido pela Netflix - bem como as ações de marketing realizadas para promover suas últimas temporadas no Brasil - e a cobertura jornalística dos eventos que levaram ao impeachment da ex-presidente eleita da República brasileira, Dilma Rousseff, e seus mais recentes desdobramentos, ligados principalmente à evolução das investigações da chamada Operação Lava-Jato. Os vínculos entre a série - que narra as artimanhas e os golpes perpetrados pelo deputado democrata Frank Underwood (Kevin Spacey) e sua esposa Claire (Robin Wright) para conquistar a presidência dos Estados Unidos e se perpetuar no poder - e a narrativa da crise brasileira são de natureza biunívoca: se, pois, por um lado, temos assistido à incursão, por parte dos personagens da série, no universo do jornalismo político brasileiro como no caso do aparecimento fictício do presidente Frank Underwood nas capas de revistas como Veja, Zero Hora e Isto é -, pelo outro, o discurso jornalístico sobre o impeachment caracterizou-se, como procurarei demonstrar, pela assunção de traços distintivos próprios do seriado norte-americano (temas, figuras, ritmos, procedimentos enunciativos, estruturas narrativas, configurações estésicas e passionais etc.).

A análise de tais sobreposições tem, na economia geral do texto, um objetivo preciso: revelar como a interseção íntima e profunda entre as duas esferas discursivas a (quase "verdadeira") dos seriados e a (quase "ficcional") do jornalismo - contribuiu, no caso brasileiro, para forjar uma realidade política cada vez mais serializada e dramatizada, construída e fruída nos moldes da ficção seriada televisiva. Constatação que, consequentemente, me induz a formular, na esteira das reflexões de Greimas e das formulações de Sedda (2012; 2016) e Demaria (2015) sobre a função mediadora entre política, mídia e vida cotidiana exercida pela televisão, uma hipótese teóricoepistemológica de caráter mais geral: a linguagem e a narrativa dos atuais dramas políticos televisivos tais quais House of Cards agem, influenciando (e interagindo com) a linguagem e o discurso jornalístico, enquanto dispositivos semióticos de 
constituição, compreensão e apreensão do real². Em outros termos, tomando emprestado um conceito caro a Jurij Lótman, eles funcionam como verdadeiros "sistemas modelizantes"3, isto é, como grelhas para a percepção, intepretação e prática do mundo em que caminhamos, trabalhamos, viajamos, votamos.

Qual é, contudo, a relação de Greimas com a problemática, as hipóteses e os escopos acima traçados? De fato, é preciso reconhecer que o vínculo entre estes e aquele pode não ser imediatamente evidente, o que me obriga, desde já, a explicitálo de maneira clara e direta.

Desenvolvendo as proposições de Semântica estrutural (GREIMAS, 1973) formuladas a partir da obra de Hjelmslev (1975), Greimas entrevê, no ensaio sobre o mundo natural mencionado em abertura (GREIMAS, 1975a), a possibilidade de um deslocamento epistemológico crucial no que tange à questão da relação entre mundo e linguagem: se para o linguista dinamarquês eram as línguas naturais a definir o recorte, a emergência e o reconhecimento das substâncias do mundo (cores, sensações, coisas em geral), para Greimas este mundo deveria ser considerado nada mais, nada menos, como um "conjunto de sistemas semióticos mais ou menos implícitos" (GREIMAS, 1975a, p. 49). Em outras palavras, em um contexto intelectual onde ainda a língua era considerada, para usarmos os termos de Lótman, o "sistema modelizante primário" (LÓTMAN, 1967) ${ }^{4}$ por excelência, Greimas move um passo decisivo rumo à dissolução dessa hierarquia, vislumbrando o peso e a contribuição de outras linguagens, textos e discursos no processo de construção da realidade - entre os quais, para voltarmos ao tema central desta pesquisa, destacam-se aqueles audiovisuais.

Outras indicações que parecem confirmar e, em certo sentido, ampliar este raciocínio encontram-se também nas entrelinhas do debate entre Greimas e Ricoeur (GREIMAS; RICOEUR, 2000). Sabe-se que o objeto da contenda entre os dois estudiosos gira entorno das noções de compreensão e explicação, bem como do papel que ambos atribuem às suas respectivas disciplinas, a semiótica e a hermenêutica, no âmbito da dialética entre as duas. Resumindo brevemente, para Ricoeur a semiótica greimasiana constitui um modelo de explicação da história e das histórias humanas, por assim dizer, de "segundo grau", que se instaura por cima de uma intuitiva e préexistente capacidade de compreensão, uma espécie de inteligência narrativa latente

${ }^{2} \mathrm{O}$ mesmo pode ser dito de seriados mais antigos, como The West Wing, e de outros mais recentes, como 24 e Homeland (Cf. SEDDA, 2016; DEMARIA, 2015).

3 (Cf. LÓTMAN; USPENSKIJ, 1975).

${ }^{4}$ Essa era também a visão do primeiro Lótman, segundo o qual a língua era, de fato, o único "sistema modelizante primário” (Cf. LOTMAN; USPENSKIJ, 1975), ou seja, com maior capacidade de dar forma ao mundo. No entanto, no final de sua trajetória, o semioticista chega a rever tal formulação, elevando também ao nível da primeira a linguagem espacial (Cf. LÓTMAN, 1996; SEDDA, 2012). 
da qual apenas a hermenêutica seria capaz de dar conta (GREIMAS; RICOEUR, 2000; RICOEUR, 1994). No entanto, como esboçou Marsciani (2000, p. 17), o que a crítica de Ricoeur não capta é o fato de que Greimas não esquece de reconhecer e abordar tal competência. Muito pelo contrário, também para o semioticista ela é um dos pressupostos da atividade e dos processos de produção de sentido. A diferença sútil - é que, para Greimas, a compreensão não é uma disposição imediata, pré ou extra semiótica, mas sim uma competência discursiva, o resultado tangível, manifestado em textos, do processo de produção de discursos de gêneros diversos, que contribuíram, ao longo dos séculos, não apenas para formar nossa propensão a acompanhar e entender histórias de qualquer tipo, como também para moldar e orientar nossa relação com o mundo dito real. Dinâmica em que, como defendo neste artigo, o enredo entre as narrativas audiovisuais jornalísticas e de ficção desenvolve um papel de primeiro plano.

Trata-se de questões às quais os mais ou menos recentes estudos pósgreimasianos - e não apenas aqueles sobre o audiovisual - não conferiram muita atenção e que merecem ser devidamente resgatadas. Além das contribuições (vastamente reconhecidas) relativas ao método, é importante frisar, hoje como nunca, as implicações e os pressupostos teórico-filosóficos (muitas vezes esquecidos) da semiótica de Greimas. Uma semiótica - é o caso lembrar - de cunho eminentemente construtivista, segundo a qual o mundo e o sujeito não existem fora da rede de linguagens e discursos em que se encontram imbricados, capaz de inspirar e coadjuvar as outras disciplinas do campo da comunicação tanto no que tange à elaboração de modelos epistemológicos gerais, quanto no que se refere à construção de macrointepretações de fenômenos de amplo alcance sociocultural, que extrapolam os confins da análise fechada de romances, quadros, fotos, filmes, programas de televisão e outros microuniversos de sentido. É exatamente isso que, com base no estudo das relações entre os novos seriados televisivos e o atual jornalismo político e sua influência na formação de nossa "realidade" e nossas "verdades" - com ou sem pós, não importa -, pretendo aqui relevar e corroborar.

\section{Mundo(s) e linguagens}

Logo nas primeiras páginas de seu ensaio Condições para uma semiótica do mundo natural, Greimas (1975a, p. 48-49) insere-se no debate entre os lógicos neopositivistas e os linguistas a respeito da problemática do referente. Enquanto os primeiros, aponta o semioticista, defendiam a tese de que existe uma referência dos nomes próprios às coisas e aos fenômenos "reais", os segundos, insistindo na primazia da contribuição das línguas 
no recorte do mundo, acabavam, em certo sentido, por hipostasiá-los, "chegando até a identificar o mundo com a linguagem” (GREIMAS, 1975a, p. 48).

O surgimento da semiótica, "teoria de todas as linguagens" (GREIMAS, 1975a, p. 48), oferece uma nova perspectiva sobre o problema, situando-o no âmbito de uma nova epistemologia. Segundo esse olhar, o mundo extralinguístico não deve mais ser considerado enquanto um simples referente,

mas como o lugar de manifestação do sensível, capaz de tornarse a manifestação do sentido humano, ou seja, da significação para o homem; em suma, tratar este referente como um conjunto de sistemas semióticos mais ou menos implícitos (GREIMAS, 1975a, p. 49).

O que, consequentemente, leva a postular:

a existência e a possibilidade de uma semiótica do mundo natural e conceber a relação entre os signos e os sistemas linguísticos ("naturais"), de um lado, e os signos e os sistemas de significação do mundo natural, de outro, não como uma referência do simbólico ao natural, do variável ao invariável, mas como uma rede de correlação entre dois níveis de realidade significantes (GREIMAS, 1975a, p. 49, grifo no original).

Greimas desloca o foco do problema sobre o tema da correlação. Nessa ótica, a questão não é se o mundo forma a língua ou se a língua forma o mundo, mas como ambos se articulam reciprocamente. Como apontou Sedda em um texto recente que reafirma a atualidade das hipóteses greimasianas no campo das ciências sociais (2017, p. 21$)^{5}$, o que importa, aqui, não é a primazia: a primazia, nessa relação, não pertence nem ao mundo nem à língua; a primazia, nessa relação, é da própria relação.

Pensar o mundo natural nem como um conjunto de coisas às quais as palavras aludem - nem, vice-versa, como um reflexo inerte da língua -, mas como uma semiótica em correlação com outra semiótica é, por si só, um ato revolucionário. No entanto, há outro aspecto da proposta de Greimas tão revolucionário quanto esse - ou talvez mais -, que gostaria aqui de abordar. A passagem do singular "linguagem" para o plural "linguagens" e a postulação do referente, isto é, do mundo extralinguístico como um nível de realidade significante constituído por uma pluralidade de "signos" e "sistemas semióticos", são traços cruciais para entendermos do que se trata e para compreenderemos, por completo, o alcance e a aposta do raciocínio greimasiano.

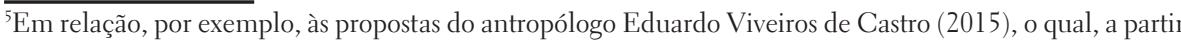
da análise das culturas amazonenses, elaborou conceitos como os de "perspectivismo" e "multinaturalismo” para explicar as diversas concretudes que o mundo assume para o homem.
} 
Como acenei na introdução, Greimas vislumbra e defende a necessidade e a legitimidade de um salto epistemológico radical: a superação do paradigma epistemológico linguístico em prol da assunção de um paradigma epistemológico propriamente e marcadamente semiótico, segundo o qual o mundo e os objetos do mundo não emergem e ganham sentido, aos olhos dos homens, apenas através de suas correlações com as línguas naturais, mas graças às interseções com uma multiplicidade de linguagens de naturezas diversas. Não por acaso, após essas primeiras considerações de caráter geral, o autor prossegue, na segunda parte do artigo, com a análise de uma das linguagens não verbais por antonomásia: a linguagem gestual, à época ainda pouco debatida no âmbito das ciências sociais estruturais. É por meio dessa investigação que as teses iniciais parecem se confirmar. Como afirma Greimas, o estudo da linguagem gestual sustenta, pois, a hipótese inicial do mundo natural enquanto mundo formado pela ação conjunta de diversos sistemas semióticos (GREIMAS, 1975a, p. 63). Longe de servir apenas à reprodução de conteúdos supostamente prefixados pelas línguas, ela possui regras específicas de produção de sentido que visam, em última instância, não apenas a auxiliar a comunicação direta entre indivíduos, mas sim, como as linguagens verbais, "à transformação do mundo" (GREIMAS, 1975a, p. 63). Razão pela qual, conclui Greimas, por se propor a descrever essas transformações, a semiótica almeja dar conta da "dimensão histórica" da realidade humana (GREIMAS, 1975a, p. 63).

Resumindo, Greimas preserva, em suas formulações, um dos fundamentos essenciais da epistemologia da linguística estrutural de matriz saussuriana ${ }^{6}$ o da existência de mundos naturais diferentes, cujo número é análogo ao número das línguas faladas ao longo da história da humanidade. Desse ponto de vista, não existe nenhum mundo "natural". As aspas que Greimas usa repetidamente para cercear o termo são, nesse sentido, altamente significativas. Para ele, o "mundo natural" - isto é, para voltarmos à terminologia utilizada neste artigo, o "mundo real" - é nada mais, nada menos que o mundo do senso comum. No entanto, diferentemente do que propõe o paradigma linguístico, o paradigma semiótico greimasiano sugere quebrar a hierarquia entre a língua e as outras linguagens, atribuindo a estas últimas a mesma função formadora e transformadora da primeira.

Ao lado de outras linguagens (gestual, pictórica, teatral, musical, fotográfica, arquitetônica, urbanística etc.), a linguagem audiovisual desenvolveu, ao longo do vigésimo século - e continua hoje desenvolvendo -, um papel determinante no processo de formação e percepção do real. Contudo, não é ainda o momento de se debruçar mais

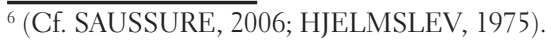


a fundo sobre tais assuntos. Antes disso, é o caso de abordar como tais hipóteses sobre o caráter semioticamente construído do mundo e da experiência humana do mundo se consolidam no diálogo entre Greimas e Ricoeur (GREIMAS; RICOEUR, 2000).

\title{
Vida(s) e narrações
}

Escreve Paul Ricoeur no primeiro volume de sua trilogia Tempo e Narrativa (RICOEUR, 1994, p. 86):

\begin{abstract}
uma ciência do texto [a semiótica do texto] [...] pode só considerar as leis internas da obra literária, sem dar atenção ao montante e à jusante do texto. E em compensação, a tarefa da hermenêutica reconstruir o conjunto das operações pelas quais uma obra eleva-se do fundo opaco do viver, do agir e do sofrer, para ser dada, por um ator, a um leitor que a recebe e assim muda seu agir.
\end{abstract}

Trata-se de um trecho fundamental, que expõe e sintetiza o nó central da posição do hermeneuta em relação à teoria de Greimas. Como já antecipei, para Ricoeur a semiótica greimasiana poderia apenas almejar explicar as regras de organização internas dos textos. Problemas como a emersão de uma obra - e Ricoeur não se refere aqui apenas à criação autoral, mas também às condições histórico-culturais de seu surgimento -, sua compreensão e recepção ficariam fora de seu alcance. Como ele próprio afirma em outra ocasião, segundo essa leitura, a semiótica constitui "um discurso racional de segundo grau, instalado por cima de uma inteligência narrativa preliminar, à qual devemos a compreensão do que se poderia chamar uma configuração narrativa" (GREIMAS; RICOEUR, 2000, p. 52, tradução minha). Compreensão - ou melhor, pré-compreensão, segundo a linguagem hermenêutica (GREIMAS; RICOEUR, 2000) -, que, como Ricoeur sugere, pode vir, em um terceiro momento, a interferir ativamente na vida das pessoas, levando-as até, muitas vezes, a mudar seu agir.

A crítica à semiótica insere-se, portanto, na reflexão sobre o célebre modelo ricoeuriano das três mimeses, que pensa a relação entre tempo e narrativa como uma evolução em três etapas, caracterizada pela passagem de um tempo "prefigurado" (mimese I) para um tempo “refigurado" (mimese III) - ambos entendidos enquanto temporalidades próprias da esfera prática da experiência vivida - através da mediação de um tempo "configurado" (mimese II), inerente ao universo das narrativas ${ }^{7}$. Se, segundo ele, a semiótica limita-se a situar a mimese II entre mimese I e mimese III e a simular, explicando-a, a racionalidade que preside à produção de sentido de um texto, a hermenêutica tende a caracterizar a configuração textual de mimese II por

$\overline{7}($ Cf. RICOEUR, 1994). 
"sua função de mediação [...] entre a prefiguração do campo prático e sua refiguração pela recepção da obra" (RICOEUR, 1994, p. 86-87).

Não é minha intenção repercorrer, em detalhe, o confronto entre os dois estudiosos. Quero me deter, ao contrário, em um aspecto da semiótica greimasiana que Ricoeur, em razão do tentativo de englobar o ponto de vista do outro no âmbito de sua teoria, parece não considerar - e que toca diretamente o cerne da reflexão que estou aqui desenvolvendo: a questão do estatuto semiótico da inteligência narrativa preliminar (a pré-compreensão) postulada por Ricoeur.

Como observa Marsciani em sua Introdução à obra que reúne os textos mais significativos do diálogo entre o semioticista e o filósofo ${ }^{8}$, do ponto de vista semiótico, a ordem ricoeuriana precisa ser invertida: a ação configurante das narrativas não resulta da pré-compreensão, mas, vice-versa, a pré-compreensão é um efeito da primeira, o resultado da ação de textos e discursos "que impõem, incessantemente, uma atividade de tradução entre linguagens, de transposições de sentido” (MARSCIANI, 2000, p. 17, tradução minha). Em outros termos, compreendemos "intuitivamente" o mundo porque nascemos, crescemos e morremos no bojo de suas histórias, interiorizando as formas de produção, articulação e organização de sentido nelas inscritas e por elas contadas, as quais, sem que o percebamos, orientam silenciosamente nossas existências.

Gostaria de seguir o caminho esboçado por Marsciani e aprofundar ulteriormente essa linha de raciocínio aportando alguns exemplos concretos extraídos da obra de Greimas. Lembro então, a este propósito, que já nas primeiras páginas de Sobre o sentido, Greimas (1975b, p. 7-17) fala abertamente da compreensão nos termos de um sentimento "natural" intimamente vinculado à onipresença do sentido e à impossibilidade, por parte do homem, de escapar de suas presas. Escreve o semioticista, em um dos trechos talvez mais significativos de sua trajetória intelectual, que parece, aliás, reformular o problema ricoeuriano em chave semiótica:

O homem vive em um mundo significante. Para ele, o problema do sentido não se coloca, o sentido é colocado, se impõe como uma evidência, um "sentimento de compreensão" absolutamente natural. Num universo branco em que a linguagem fosse pura denotação das coisas e dos gestos, não seria possível interrogar-se sobre o sentido: toda interrogação é metalinguística (GREIMAS, 1975b, p. 13). 
Sendo assim, a compreensão é um "sentimento natural" (uma inteligência narrativa ingênua, poder-se-ia dizer parafraseando Ricoeur), apenas porque existe, antes, durante e depois de nós, um universo de sentido dado - isto é, de linguagens, textos, discursos - que define nossa realidade "primeira", com o qual interagimos e que somos constantemente chamados e desafiados a construir, descontruir e reconstruir.

Os ecos de tais ideias - explícita ou implicitamente - se alastram em toda a obra de Greimas. É o que se pode constatar nas entrelinhas de textos como Da Imperfeição e Le Beau Geste (O belo gesto). Se, nas últimas páginas do primeiro, Greimas (2002, p. 84) nos exorta a trocar "os signos por gestos" e a buscar uma nova vivência do cotidiano que traduza, dessacralizando-as, as fraturas estésicas descritas no discurso literário, no segundo a exigência de pensar a experiência e a narração como fenômenos imbricados e sobrepostos torna-se ainda mais evidente: é o que demostram as páginas sobre Alfred Jarry, cujo último pedido antes de sua morte um palito de dente - é absolutamente coerente, lembra Greimas, com o conceito de "absurdo" que definiu o norte de sua narrativa teatral'.

Nesse sentido, voltando a Ricoeur, a ação refigurada (mimeses III) a partir da narração configurante (mimeses II) torna-se, como defende Sedda (2012, p. 240, tradução minha), "o espaço tempo de uma nova mimese I que inspira[rá] novos atos configurantes": o momento-lugar, em outras palavras, da emergência de uma nova realidade intrinsicamente narrativizada - e que passa, aos poucos, a ser percebida como natural -, suscetível de proporcionar, em futuro, o surgimento de novas narrações.

Apresenta-se aqui um problema parecido com aquele, discutido no item anterior, relativo à ordem da relação entre língua e mundo. Resumindo banalmente: os textos imitam a vida ou a vida imita os textos? Levando até as extremas consequências o raciocínio de Greimas, poderia se dizer que esta não é uma pergunta pertinente sob o perfil semiótico-discursivo. O que importa, mais uma vez, não é a preeminência dos textos sobre a vida ou vice-versa. O que importa é a forma de sua correlação. Forma que, longe de evoluir em linha reta ou circular, apresenta-se como um quiasmo: se é verdade, por um lado, que nossas histórias são histórias de vida, é certo, pelo outro, que nossas vidas são vidas de histórias. E hoje nossas vidas, nossas histórias, nossos mundos e nossas realidades são, antes de mais nada, vidas, histórias, mundos e realidades seriais.

$\overline{9(\text { Cf. GREIMAS, 1995). }}$ 


\title{
Realidades seriais
}

Entre as narrativas seriais que moldam nossa realidade e orientam nossa apreensão do mundo, os dramas políticos televisivos ocupam um lugar privilegiado. Como afirma Cristina Demaria, mais que qualquer outra, as

\begin{abstract}
narrações seriais de gênero político contribuem à definição de frames de referência e modelos de memória e ação, interferindo, assim, na maneira como, enquanto espectadores e, possivelmente, enquanto cidadãos, adquirimos ferramentas para interpretar o próprio campo da política (DEMARIA, 2015, p. 2, tradução minha).
\end{abstract}

Demaria embasa sua reflexão em um pressuposto teórico-epistemológico fundamental, desenvolvido recentemente em chave semiótica por Eugeni (2010), segundo o qual a experiência do homem contemporâneo é essencialmente uma “experiência medial". Desse ponto de vista, as mídias não devem ser entendidas enquanto meros dispositivos de saber e de poder, mas como verdadeiras próteses, que regulam e modulam "a percepção e a compreensão do mundo e de seu sentido" (DEMARIA, 2015, p. 2-3, tradução minha).

Na mesma diretriz, Sedda (2016, p. 164, tradução minha), defende que "os seriados televisivos norte-americanos, e aqueles políticos de modo particular, tornaram-se o espelho da nação". Um espelho, no entanto - e é esse o nó da questão - que não se limita a refletir e a representar os processos políticos e sociais, mas que cumpre, paralelamente, um verdadeiro papel "mágico e performático, no qual o povopúblico se reflete para renascer dia após dia” (SEDDA, 2016, p. 164, tradução minha).

As posições de Sedda e Demaria me interessam por duas razões específicas e interligadas. Em primeiro lugar, porque (ainda que, no caso de Demaria, sem afirmálo diretamente) ambos os semioticistas inserem-se no âmago da trajetória teórica traçada por Greimas, declinando-a, especificamente, no campo das relações entre ficção seriada televisiva e realidade política atual - trajetória que eu, ao contrário, me propus aqui a explicitar e reformular. Em segundo lugar, porque elas se apresentam como um frutífero ponto de partida para construir a ponte entre a releitura da epistemologia greimasiana, conduzida na primeira parte do artigo, e a análise das imbricações entre House of Cards e a cobertura jornalística da crise política que culminou no (e seguiu o) impeachment de Dilma Rousseff, através das quais, como disse na introdução, ganhou corpo no Brasil a percepção de uma realidade políticosocial altamente dramatiza e serializada. 


\section{De House of Cards à política brasileira (e vice-versa)}

Dia 17 de abril de 2016 é um marco crucial da crise política que, desde as manifestações de junho 2013, vem abalando o Brasil ${ }^{10}$ : ao vivo na Rede Globo, sob o eco dos manifestantes divididos por um muro na Esplanada dos Ministérios de Brasília, a Câmara dos Deputados do Congresso Nacional Brasileiro pronuncia-se a favor da abertura do processo de impeachment da presidente Dilma Rousseff, eleita em 2014 com $51,64 \%$ das preferências.

Pouco mais de um mês antes, no começo de março de 2016, a Netflix lança a quarta temporada de House of Cards. No Brasil, as estratégias de promoção da série giram em torno de um motivo preciso: a ancoragem ao contexto político-institucional local ${ }^{11}$.

No dia 4 de março de 2016, as revistas Veja e Carta Capital e os jornais O Povo, Zero Hora e Gazeta do Povo publicam em seus perfis no Facebook e Twitter uma série de capas e reportagens fictícias (publieditoriais), encomendadas pela Netflix, sobre a trajetória política de Frank Underwood e suas intenções em relação à política externa estadunidense. As capas da Veja e do Zero Hora, em particular, fazem explícita referência ao cenário brasileiro: "O triunfo de Frank: o que a surpreendente campanha do presidente americano pode ensinar ao Brasil" é o título da primeira, enquanto o segundo destaca, entre aspas, uma declaração do próprio Underwood, "Política Brasileira tem que aprender com a dos Estados Unidos", que alude a um dos programas promovidos pelo presidente-personagem (America Works) para reduzir as elevadas taxas de desemprego de seu estado, potencialmente replicável, como se infere de suas palavras, ao sul da linha equatorial.

No entanto, essa não é a única forma através da qual o universo narrativo ficcional de House of Cards penetrou na "realidade" do Brasil e nos meios encarregados de contar e apresentar "objetivamente" fatos e acontecimentos "verdadeiros". Longe de se limitar a ocupar, por meio de uma ação de marketing explícita e facilmente reconhecível enquanto tal, o espaço de algumas das mais lidas revistas e dos mais lidos jornais da cena nacional, o universo do seriado alastrou-se nas tramas da vida política e do discurso jornalístico brasileiro de modo ainda mais direto e consistente, propondo-se e funcionando, parafraseando Demaria (2015), como um frame, isto é, como uma moldura e uma lente para a intepretação e a apreensão do atual cenário político do país.

A quantidade de títulos, chamadas, matérias, reportagens (e assim por diante) que mencionam e utilizam - direta ou indiretamente - House of Cards e o

\footnotetext{
${ }^{10}($ Cf. DEMURU, 2017).

${ }^{11}$ (Cf. ALZAMORA; DIAS; BARROS, 2016).
} 
universo da ficção seriada televisiva como referência para ler, interpretar e narrar a crise brasileira é considerável. Expressões como "House of Cunha"12 - em referência às articulações promovidas pelo ex-presidente da Câmara, Eduardo Cunha, para derrubar Rousseff - e títulos como "As semelhanças entre House of Cards e a política brasileira" (AS SEMELHANÇAS..., 2016) povoam as capas e as telas de importantes jornais nacionais e internacionais. No Brasil, o blog Buzzfeed publicou um post que desloca explicitamente os eventos políticos no plano da ficção: "E se o impeachment fosse uma novela das oito? Quando a realidade supera a ficção, já pode ir escolhendo os atores" (EVANGELISTA; BAREM, 2016), enquanto o jornal on-line Nexo lançou em seu site a seguinte enquete: "Quiz: Aconteceu em Brasília ou em 'House of Cards'?” (RONCOLATO, 2016), o que comprova o grau e a intimidade da compenetração entre os dois mundos. Seria impensável, portanto, reconstruir e analisar aqui, em detalhe, um corpus tão extenso. Existem, contudo, alguns exemplos-chave que resumem de maneira emblemática o papel configurante e refigurante, para dizê-lo com Ricoeur (1994), que a série exerceu com relação à cobertura da crise. Sem me deter em descrições minuciosas de cada um - o que foge dos escopos deste artigo -, citarei aqui dois casos nos quais essa relação ganhou contornos nítidos e sentidos claros e um terceiro em que ela não aparece de maneira tão evidente, mas cujos arranjos narrativos condensam bem a cifra dessa sobreposição e podem ajudar a situar e a entender como, na esteira das sugestões epistemológicas de Greimas, apreendemos nossa realidade a partir das interações que entretemos com os textos e dos discursos que nela circulam ${ }^{13}$.

Em 31 de agosto de 2016 - dia em que o Senado brasileiro sancionou e efetivou, com seu voto positivo, a precedente decisão da Câmera sobre o impeachment de Dilma - foi ao ar, na edição das 18h do Jornal da GloboNews, uma reportagem-resumo de 12 minutos sobre a trajetória política que conduziu à destituição da ex-presidente eleita. Leilane Neubarth, âncora do jornal, introduziu o vídeo com a seguinte fala:

Nos últimos meses, a política no Brasil foi muito comparada aos seriados americanos. Foram escândalos, surpresas, reviravoltas, notícias que pipocavam a todo momento. Se você piscasse o olho poderia perder uma informação. Foi criada até aquela expressão "Jornalismo Novela" e a GloboNews acompanhou cada capítulo desta trama. Uma trama de dar inveja a muitos roteiristas de ficção. E uma história que ainda está longe de terminar. (GLOBONEWS..., 2016)

\footnotetext{
12(Cf. SEQUEIRA; TORRES, 2016).

${ }^{13}$ (Cf. LANDOWSKI, 2016).
} 
Os segundos iniciais da reportagem-resumo reproduzem, tanto sob o perfil rítmico (tempos de montagens curtos, passagens rápidas etc.), quanto sob aquele narrativo (individuação precisa dos actantes/atores em jogo e criação de expectativas em relação ao desenvolver-se dos eventos), os primeiros instantes de um qualquer novo episódio de seriado norte-americano. É o momento em que o telespectador é atualizado sobre o que aconteceu nos capítulos anteriores e introduzido, não por acaso, por uma voz-off que anuncia: "Previously on..." (literalmente, "anteriormente em...”). Logo depois, as imagens são interrompidas por uma verdadeira abertura: um após o outro, com os sons de um sintetizador que lembra certa música eletrônica dos anos oitenta e por cima de letras (P, B, S etc.) iluminadas como letreiros neon, aparecem os nomes dos políticos-protagonistas da "novela" do impeachment: Eduardo Cunha, Dilma Rousseff, Michel Temer, Renan Calheiros, Lula, Ricardo Lewandowski. Em seguida, surge o título da reportagem: "Política no Brasil". Tratase de uma alusão intertextual (FIORIN, 2003): a abertura da "série" Política no Brasil produzida pela GloboNews lembra, pois, a abertura de um outro seriado de sucesso da Netflix: Stranger Things, thriller de ficção científica que conta a história de um grupo de crianças em busca de um amigo perdido em uma realidade paralela.

São apenas os primeiros de uma série de elos intertextuais e interdiscursivos que se alastram pela reportagem inteira, em que prevalecem citações e alusões aos arranjos narrativos e figurativos de House of Cards. Emblemáticas, a esse propósito, as cenas em que aparecem os edifícios dos poderes do Estado brasileiro (Congresso e Palácio do Planalto) atravessados por nuvens em movimento, assim como acontece com a Casa Branca na abertura do seriado norte-americano.

Outro texto jornalístico cita explicitamente o mundo ficcional da Netflix: a capa da edição do dia 13 de abril de 2017 do jornal Metro de São Paulo, cuja configuração plástico-figurativa reproduz aquela da plataforma de streaming, com a imagem de um personagem em destaque no centro da página (nesse caso, Marcelo Odebrecht) e, mais abaixo, uma série de fotogramas de outros vídeos "adicionados recentemente" nos quais o usuário/leitor é convidado a clicar. Assim como essa disposição, o título "Delaflix: Brazilian Horror Story" - deixa claro o programa narrativo do enunciador: contar a evolução da crise político-institucional brasileira (e, especificamente, o avanço e a divulgação, em vídeo, das delações da chamada Operação Lava Jato) como se fosse um "verdadeiro" drama político, tal qual House of Cards.

O terceiro exemplo, como antecipei, é menos patente e circunscrito. É o caso das diversas edições do Jornal Nacional da Rede Globo dedicadas, em maior parte, aos eventos que marcaram o percurso rumo ao impeachment de Dilma, a 
começar pela edição de 16 de março de 2016, na qual foram divulgadas as conversas entre Rousseff e Luiz Inácio Lula da Silva, convidado pela presidente a integrar o governo como novo ministro da Casa Civil. Como observou Rocha (no prelo), estamos diante de um discurso cujo "efeito de objetividade [...] se baseia na incorporação de muitos elementos melodramáticos pela narrativa”. As considerações de Mota Rocha se cruzam aqui com as propostas de Demaria sobre os mecanismos de "enquadramento" da nossa experiência do mundo proporcionados por House of Cards. Ambos utilizam, nesse sentido, estratégias parecidas, fundadas nos pilares da narratividade, assim como postulados por Greimas (1975c) - individuação de sujeitosheróis (o juiz Sergio Moro) e antissujeitos/anti-heróis (Dilma e Lula), de programas narrativos (a obtenção do poder) e sanções coletivas (institucionais e populares) -, e motivos temáticos e estésico-passionais específicos, entre os quais destaca-se, nos dois casos, o cinismo: assim como House of Cards, "que reelabora a crise e o drama da política transformando-a em uma espécie de darwinismo social" (DEMARIA, 2015, p. 18, tradução minha), a cobertura jornalística da crise brasileira apresenta, muitas vezes, uma das partes em jogo na contenda (a da ex-presidente e seu partido), como um sujeito movido exclusivamente pela cobiça e pela sede de poder.

Resumindo, é possível afirmar que o discurso jornalístico brasileiro traduziu e absorveu o mundo de House of Cards e, em geral, da ficção seriada da era Netflix de três formas distintas e inter-relacionadas:

- a) incorporando configurações e traços plásticos, rítmicos e figurativos típicos da linguagem televisiva (como no caso de "Política no Brasil" e da capa do jornal Metro);

- b) reproduzindo e ecoando estruturas narrativas clássicas da cultura ocidental (como bem demonstra a cobertura do Jornal Nacional);

- c) construindo uma cobertura, por assim dizer, marcadamente "serial", constituída de tramas, acontecimentos e clímax que se alastram, muitas vezes sem se resolverem, capítulo após capítulo. A fala de Leilane Neubarth ("Foi criada até aquela expressão 'Jornalismo Novela' e a GloboNews acompanhou cada capítulo desta trama”) é, a respeito deste último ponto, altamente significativa. 
O que importa evidenciar, no entanto, é outra questão. Uma questão que vai direto ao coração do problema e das hipóteses apresentadas neste texto, e que, de um jeito que não deixa de ser paradoxal, é luminada justamente pelas palavras de Neubarth: longe de limitar-se a "acompanhar" os capítulos da novela política brasileira, a GloboNews, o Jornal Nacional e o discurso jornalístico brasileiro foram, de fato, seus autores e roteiristas ${ }^{14}$. O que eles construíram e encenaram é, pois, uma realidade novelesca-serial que nós, enquanto cidadãos, apreendemos e consumimos enquanto tal, tecendo conexões com os textos e as narrativas dominantes de nossa época (SEDDA, 2016). Voltando a Greimas, entre o mundo dos textos e dos discursos - sejam aqueles de ficção, sejam aqueles que se propõem a expor os fatos reais - e o mundo da vida não há solução de continuidade. Ao contrário, há vínculos e imbricações mais profundas do que se possa pensar. Demonstra-o a quantidade incalculável de memes criados pelos usuários e ativistas brasileiros de Facebook e Twitter que utilizam o enredo e os personagens da série para ironizar sobre as peripécias dos protagonistas da política nacional contadas pela mídia ${ }^{15}$ ou, ainda, a própria incorporação, nas estratégias de marketing da Netflix, dos eventos "reais" do Brasil (como quando, em 30 de maio de 2017, aproveitando da divulgação das conversas entre Temer e o empresário Joesley Batista, que traziam à tona o envolvimento do presidente e de seu partido no esquema de propinas elaborado pela JBS e investigado no âmbito da Lava Jato, o colosso do audiovisual norte-americano postou, em seus perfis nas redes sociais, um vídeo-anúncio protagonizado por Doug Stamper, chefe de gabinete de Underwood interpretado por Michael Kelly, em que o personagem dirigia-se aos brasileiros com as seguintes palavras: “ao povo brasileiro: esta não é uma competição. Vocês não sabem de onde as pessoas podem tirar inspiração. Fiquem atentos").

\section{Conclusões}

Habitamos histórias e linguagens, e as histórias e as linguagens nos habitam. É talvez essa a primeira conclusão que é possível tirar da análise da conjuntura acima desenvolvida. No entanto, as sobreposições recíprocas entre a ficção seriada televisiva e a cobertura jornalística dos eventos que precederam e seguiram o impeachment de Dilma Rousseff nos convidam a retornar, com mais calma e cuidado, sobre as questões epistemológicas colocadas na introdução e às quais procurei dar corpo e respaldo ao longo de todo o artigo.

\footnotetext{
${ }^{14}$ (Cf. BENTES, 2016).

${ }^{15}$ (Cf. AQUINO BITTENCOURT; GONZATTI, 2016).
} 
A esse propósito, duas são as coisas que me parece possível afirmar. A primeira é que, hoje como nunca, à luz do atual cenário midiático-comunicacional, é preciso reconsiderar e reelaborar séria e detalhadamente as bases epistemológicas da semiótica de Greimas. Uma semiótica, repito, segundo a qual o mundo e a nossa experiência - inteligível e sensíve ${ }^{16}$ - do mundo não são nunca naturais, mas sim o resultado - que poderá sim, um dia, vir a ser naturalizado - da correlação (GREIMAS, 1975a) entre séries potencialmente infinitas de linguagens, textos e discursos, cujos números, pesos e papeis não são nunca definidos a priori, mas variam conforme o tempo, o lugar e as narrações em que nos situamos e transitamos.

A segunda é que é preciso levar tais bases até suas extremas consequências e reafirmar, antes de mais nada, a primazia da relação sobre os termos. Ou melhor, a primazia das correlações entre os termos. E não apenas no estudo das linguagens verbais, audiovisuais etc., como também na análise dos processos midiáticos e comunicacionais contemporâneos, caracterizados, cada vez mais, pelo vínculo profundo entre experiência e narração. Capitulo após capitulo, declaração após declaração, meme após meme, a série-novela da crise política brasileira mostrou exatamente isto: a compenetração profunda e recíproca tanto entre discursos de gêneros diversos (ficção seriada televisiva e jornalismo político) quanto, e principalmente, entre mundo "real" e mundo "ficcional", em particular aquele de House of Cards. Se, pois, como vimos, em determinados momentos foi a série que se adentrou no universo "verdadeiro" dos jornais, em outros foi a "realidade" jornalística brasileira que invadiu o universo ficcional da série, cujo roteiro e cujas tramas, como afirmaram os próprios personagens, deixaram de competir com os "fatos" para, ao contrário, estudá-los e tirar deles inspiração. Compenetração que, consequentemente, me levou a reformular o debate entre Greimas e Ricoeur (2000), insistindo não mais na linearidade da relação entre vida e textos, mas sim sobre sua circularidade e as correlações entre os dois.

Assim delineada, a epistemologia semiótica apresenta-se, por um lado, como uma epistemologia "hiperestruturalista" (Sedda, 2017, p. 29), que põe no cerne de sua atividade teórica e analítica a problemática da correlação e, pelo outro, se me é permitido acrescentar, como uma epistemologia "hiperconstrutivista", fundada em uma recusa radical de qualquer "natureza", "realidade" ou "verdade" pura - física, biológica, comunicacional, midiática etc. Uma epistemologia, para utilizarmos os termos de Eric Landowski (2016), intrinsicamente sociossemiótica, que vê e aborda o mundo real e midiático não como objetos fechados e autossuficientes, mas com

$\overline{{ }^{16}(\text { Cf. GREIMAS, 2002) }}$ 
foco nas interações que os sujeitos constroem com eles, dentro deles, ao redor deles e entre eles. Uma epistemologia pela qual o real, assim como o verdadeiro, é em território em disputa, um espaço discursivo que se define na encruzilhada de uma multiplicidade de linguagens e narrações e a partir das relações de força em jogo em uma determinada esfera sociocultural.

\section{Referências}

ALZAMORA, G. C.; DIAS, E.; BARROS, V. "A dinâmica transmídia de House of Cards no contexto político brasileiro". Culturas Midiáticas, João Pessoa, v. 9, n. 17, p. 189-203, jul./dez. 2016.

AQUINO BITTENCOURT, M. C.; GONZATTI, C. "House of memes: midiatização do ativismo e transformações no jornalismo a partir de uma (ciber)cultura pop". Revista Geminis, São Carlos, v. 7, n. 1, p. 101-116, jul. 2016.

BENTES, I. "Mídia brasileira construiu narrativa novelizada do impeachment". The Intercept Brasil, Rio de Janeiro, $1^{\circ}$ set. 2016. Disponível em: <https://goo.gl/ mXYwjb>. Acesso em: 20 out. 2017.

DEMARIA, C. "Political Dramas e drammi della politica in tempi di crisi: House of Cards e dintorni". Between: Rivista dell'Associazione di Teoria e Storia Comparata della Letteratura, Cagliari, v. 5, n. 10, p. 1-20, nov. 2015.

DEMURU, P. Impeachment, bandeiras e futebol: o campo político brasileiro à luz da semiótica. In: Colóquio Internacional Greimas. Desenvolvimentos, apropriações e desdobramentos para uma semiótica das práticas, 1., 2017, São Paulo. Anais... São Paulo, 2017.

EVANGELISTA, R.; BAREM, M. "E se o impeachment fosse uma novela das oito?". Buzzfeed Brasil, São Paulo, 31 ago. 2016. Disponível em: <https://goo.gl/FDLSpC>. Acesso em: 20 out. 2017.

EUGENI, R. Semiotica dei media: le forme dell'esperienza. Roma: Carocci, 2010.

FIORIN, J. L. "Polifonia textual e discursiva". In: BARROS, D. L. P.; FIORIN, J. L. (Orgs.). Dialogismo, polifonia e intertextualidade em torno de Bakhtin. 2. ed. São Paulo: Edusp, 2003. p. 30-36.

GLOBONEWS mostra um pouco da política no Brasil nos últimos meses. Jornal da GloboNews, São Paulo, 31 ago. 2016. Disponível em: <https://goo.gl/Anlxjs >. Acesso em: 31 out. 2017.

GREIMAS, A. J. Semântica estrutural: pesquisa de método. Tradução Haquira Osakabe e Izidoro Bilkstein. São Paulo: Cultrix, 1973.

"Condições para uma semiótica do mundo natural". In: Sobre o sentido: ensaios semióticos. Tradução Ana Cristina Cruz Cezar et al. Petrópolis: Vozes, 1975a. p. 46-85.

"Sobre o sentido". In: Sobre o sentido: ensaios semióticos. Tradução 
Ana Cristina Cruz Cezar et al. Petrópolis: Vozes, 1975b. p. 7-17.

Sobre o sentido: ensaios semióticos. Tradução Ana Cristina Cruz Cezar et al. Petrópolis: Vozes, 1975c.

"Il bel gesto". In: POZZATO, M. P. (Org.). Estetica e vita quotidiana. Milano: Lupetti, 1995. p. 59-75.

. Da imperfeição. Tradução Ana Claudia de Oliveira. São Paulo: Hacker, 2002.

GREIMAS, A. J.; RICOEUR, P. Tra ermeneutica ed semiotica. Tradução Francesco Marsciani. Roma: Meltemi, 2000.

LANDOWSKI, E. "Entre comunicação e semiótica, a interação". Parágrafo, São Paulo, v. 4, n. 2, p. 207-217, jul./dez. 2016.

LÓTMAN, J. M., “Tesi sull'arte come sistema secondario di modellizzazione”. In: LÓTMAN, J. M.; USPENSKIJ, B. A. Semiotica e cultura. Tradução Donatella Ferrari-Bravo. Milano; Napoli: Ricciardi, 1967. p. 3-27.

"El texto y el poliglotismo de la cultura". In: La semiosfera: semiótica de la cultura y del texto. Tradução Desiderio Navarro. Madrid: Cátedra, 1996. v. 1, pp. 83-90.

LÓTMAN, J. M.; USPENKIJ, B. A. Tipología della cultura. Tradução Remo Faccani e Marzio Marzaduri. Milano: Bompiani, 1975

HJELMSLEV, L. T. Prolegômenos a uma teoria da linguagem. Tradução José Teixeira Coelho Netto. São Paulo: Perspectiva, 1975.

MARSCIANI, F. “Introduzione”. In: GREIMAS, A. J.; RICOEUR, P. Tra ermeneutica e semiotica. Tradução Francesco Marsciani. Roma: Meltemi, 2000. p. 7-19.

ROCHA, M. M. E. O monopólio social da "nação": O Jornal Nacional e o rito de destituição de Dilma Rousseff. No prelo.

RICOEUR, P. Tempo e narrativa: Tradução Constança Marcondes Cesar. Campinas: Papirus, 1994. v. 1.

RONCOLATO, M. “Quiz: aconteceu em Brasília ou em ‘House of Cards'?”. Nexo, São Paulo, 24 abr. 2016. Disponível em: <https://goo.gl/4vuh6N>. Acesso em: 20 out. 2017.

SAUSSURE, F. Curso de linguística geral. Tradução Antonio Chelini, José Paulo Paes e Izidoro Bilkstein. 27. ed. São Paulo: Cultrix, 2006.

SEDDA, F. Imperfette traduzioni: semiopolitica delle culture. Roma: Nuova Cultura, 2012.

"La fatíca della fática. Interazioni mediali, questioni semiopolitiche". $\overline{\text { Intexto, }}$ Porto Alegre, n. 37, p. 152-175, set./dez. 2016.

"Relationalism: from Greimas to hyperstructuralism". Sign system studies, Tartu, v. 45, n. 1-2, p. 16-32, jul. 2017. 
AS SEMELHANCAS entre "House of Cards" e a política brasileira. Diário de Notícias, Lisboa, 18 mar. 2016. Disponível em: <https://goo.gl/9VCf33>. Acesso em: 20 out. 2017.

SEQUEIRA, C. D.; TORREZ, I. "House of Cunha”. Istoé, São Paulo, 21 jan. 2016. Disponível em: <https://goo.gl/TL2Y5e> . Acesso em: 20 out. 2017.

\section{Referências audiovisuais}

HOUSE of Cards. Criação: Beau Willimon. Estados Unidos, 2013-2017.

STRANGER Things. Criação: Matt e Ross Duffer. Estados Unidos, 2016-2017.

submetido em: 15 ago. 2017 | aprovado em: 28 set. 2017 